\title{
Characterization of Antioxidant Compound from Syzygium polyanthum Leaves Extract Using UHPLC-HRMS
}

\author{
Mohamad Ana Syabana ${ }^{1,2}$, Nancy Dewi Yuliana ${ }^{1,4,5^{*}}$, Irmanida Batubara ${ }^{3,4}$, Dedi Fardiaz ${ }^{1}$ \\ 1 Department of Food Science and Technology, IPB University, Bogor, Indonesia. \\ ${ }^{2}$ Department of Food Technology and Indonesian Center of Excellence for Food Security, \\ Sultan Ageng Tirtayasa University, Serang, Indonesia. \\ ${ }^{3}$ Department of Chemistry, Faculty of Mathematics and Natural Sciences, IPB University, Bogor, Indonesia \\ ${ }^{4}$ Tropical Biopharmaca Research Center, IPB University, Bogor, Indonesia. \\ ${ }^{5}$ Halal Science Center, IPB University, Bogor, Indonesia
}

*Corresponding author email: nancy_dewi@ipb.ac.id; nancy_dewi@apps.ipb.ac.id

Received June 15, 2020; Accepted February 20, 2021 ; Available online March 25, 2021

\begin{abstract}
The leaves of Syzygium polyanthum is widely used in Indonesia as a spice. It has been reported to have significant antioxidant activity. However, the reports on compounds responsible for the activity are very scarce. The purpose of this research was to characterize the chemical profile of $S$. polyanthum extracts which showed the highest antioxidant activity. The dried leaves of $S$. polyanthum were extracted using different combination of non-polar to polar solvent $(n-$ hexane, acetone, and water, respectively). Fourteen extracts were collected and analyzed for their DPPH antioxidant activity. The chemical profile of selected extracts was characterized using UHPLC-HRMS to identify compounds that might associate with antioxidant activity of S. polyanthum. The results showed that at the concentration of $500 \mu \mathrm{g} / \mathrm{mL}$, four extracts showed the highest antioxidant activity with the following order: E9 (acetone:water=80:20), E10 (acetone:water=60:40), E1 (hexane $100 \%$ ) and E3 (hexane:acetone $=80: 20$ ). UHPLC-HRMS analysis successfully identified several compounds in E9 and E10. Trans-aconitic acid and gallic acid, were identified in E9 and E10, while myricetin was identified only in E9. All of the identified compounds were previously reported to have antioxidant activity
\end{abstract}

Keywords: Antioxidant, spices, Syzygium polyanthum, UHPLC-HRMS.

\section{INTRODUCTION}

Syzygium polyanthum leaves, or salam leaves, is very common condiment in Indonesian cuisine to enhance the aroma and flavor, especially the mature leaves that have a stronger aroma (Ismail \& Wan Ahmad, 2019). The main volatile compounds from $S$. polyanthum leaf extract are $\beta$-panasinsene, phytol, squalene, $\alpha$-cubebene and $\alpha$-pipene (Rahim, Ismail, Omar, Rahmat, \& Ahmad, 2018).

Other than that, S. polyanthum leaves are also empirically used by Indonesians for various pharmacological purposes. For example, in Riau (Sumatra Island, Indonesia), S. polyanthum leaves are traditionally added in soup to treat hypertension (Grosvenor, Gothard, McWilliam, Supriono, \& Gray, 1995). This evidence was scientifically proven by the ability of ethanol extract of $S$. polyanthum leaves to inhibit the activity of Angiotensin-converting enzyme by $53.37 \%$ at the concentration of $100 \mu \mathrm{g} / \mathrm{mL}$ (in vitro) (Muthia, Suganda, \& Sukandar, 2017). The leaves of this plant were also reported to have antidiabetic activity by inhibiting the activity of $\alpha$-glucosidase enzyme ( $\left(\mathrm{C}_{50} 19.06 \mu \mathrm{g} / \mathrm{mL}\right)$ and reducing blood sugar in diabetic rats (Elya et al., 2015; Widyawati, Yusoff, Asmawi, \& Ahmad, 2015). Flavonoids extracted from S. polyanthum leaves were also reported to have cytotoxic activity in mouse colon 26 adenocarcinoma cells and HB4C5 human hybridoma (Sulistiyani et al., 2014).

Many studies presumed that the pharmacological characteristics of plants are related to their antioxidant activity (Hassan et al., 2014; Islam et al., 2020; Loodu \& Rupasinghe, 2019). In quantitative biological research, the Pearson analysis was commonly used to determine the correlation between two parameters (Yadav, 2018). The antioxidant activity of ethanol and hot water extract of Myrica gale L., Rhodiola rosea L., Rumex acetosa L., Utrica dioica L., and Taraxacum officinale L. was significantly correlated with antidiabetic and antiobesity through inhibition of $\alpha$ glucosidase enzyme and advanced glycation end products, respectively (Loodu \& Rupasinghe, 2019). Another study reported that radical scavenging activity of ethanol extract of Heritiera fomes was also showed strong correlation with anti-inflammatory activity through inhibition of red blood cell lysis and reduction 
of mice paw edema (Islam et al., 2020). Flavonoid containing extract from S. polyanthum leaves, which was reported to have significant cytotoxic activity in mouse colon 26 adenocarcinoma cells and HB4C5 human hybridoma, also had high antioxidant activity. Unfortunately, the structure of flavonoids was not identified in this study (Sulistiyani et al., 2014).

There are a number of reports on antioxidant activity of $S$. polyanthum leaves. The methanol and ethyl acetate extract of $S$. polyanthum leaves were reported to have antioxidant activity with $\mathrm{IC}_{50}$ values between 17.46-24.09 $\mathrm{mg} / \mathrm{mL}$ (Har \& Ismail, 2012; Perumal, Mahmud, Piaru, Chai, \& Ramanathan, 2012; Widyawati, Roslan, Yusoff, Asmawi, \& Ahmad, 2016) and $13.70 \mu \mathrm{g} / \mathrm{mL}$ (Darusman, Wahyuni, \& Alwi, 2013), respectively. Another research reported that the $\mathrm{IC}_{50}$ of antioxidant activity of methanol and ethyl acetat extracts of $S$. polyanthum leaves was 44.35 and $56.7 \mu \mathrm{g} / \mathrm{mL}$, respectively (Hidayati, Ersam, Shimizu, \& Fatmawati, 2017). These results indicated that the antioxidant activity of $S$. polyanthum leaves could be grouped as a highly active category because its $I_{50}$ value is between $10-50 \mu \mathrm{g} / \mathrm{mL}$ (Phongpaichit et al., 2007). However, the researches which reported compounds responsible for the activity are still limited.

The objective of this study was to determine the DPPH antioxidant activity of $S$. polyanthum leaves extract with some difference solvent and characterize the chemical composition of extract of $S$. polyanthum leaves with the highest antioxidant activity. The extract were generated using gradient extraction with nonpolar (n-hexane), semi-polar (acetone), polar (water), and the mixture of hexane-acetone and acetone-water solvents. The active extract was further analyzed using UHPLC-HRMS to identify compounds which might be responsible for its antioxidant activity.

\section{EXPERIMENTAL SECTION \\ Materials}

The material used in this study was the leaves of $S$. polyanthum (Salam Leaves), which taken from the experimental garden of the Tropical Biopharmaca Research Center, IPB University. The leaves used were the fifth leaves after the shoots which were classified as mature leaves.

\section{Samples Preparation}

S. polyanthum leaves were immediately frozen in the freezer $-20{ }^{\circ} \mathrm{C}$ for 48 hours. The samples were then dried with a freeze dryer for 48 hours and stored in the freezer until the extraction process.

\section{Extraction}

The extraction was performed following the procedure previously described (Yuliana, Khatib, Verpoorte, \& Choi, 2011) with solvent modification. The dried samples were powdered, sieved (20 mesh), and then subjected to the extraction process. One gram of $S$. polyanthum leaf powder was mixed with 4 grams of sea sand (Wako pure chemical) and put into a $5 \mathrm{~mL}$ stainless steel column and covered with cellulose membrane. The extraction process was carried out by pumping the solvent into the column at 1500 psi in accelerated solvent extractor (Dionex ASE 350).

The solvents were flowed stepwise, starting from $100 \% n$-hexane (non-polar), a combination of hexane-acetone, $100 \%$ acetone (semi-polar), a combination of acetone-water and $100 \%$ water (polar) (Table 1). These extraction processes resulted in 14 extracts and this step was repeated 3 times to obtained 42 extracts. The organic solvent was evaporated from the extract using $\mathrm{N}_{2}$ gasses, while water was removed using freeze-dried. The dried extract was weighed to get the yield of the extracts.

Table 1. Solvent gradient which was used in extraction process

\begin{tabular}{clc}
\hline No extracts & \multicolumn{1}{c}{ Solvent profile } & Abbreviation \\
\hline 1 & Hexane $100 \%$ & E1 \\
2 & Hexane $100 \%$ & E2 \\
3 & Hexane:Acetone $=80: 20$ & E3 \\
4 & Hexane:Acetone $=60: 40$ & E4 \\
5 & Hexane:Acetone $=40: 60$ & E5 \\
6 & Hexane:Acetone $=20: 80$ & E6 \\
7 & Acetone $100 \%$ & E7 \\
8 & Acetone $100 \%$ & E8 \\
9 & Acetone:Water $=80: 20$ & E9 \\
10 & Acetone:Water $=60: 40$ & E10 \\
11 & Acetone:Water $=40: 60$ & E11 \\
12 & Acetone:Water $=20: 80$ & E12 \\
13 & Water $100 \%$ & E13 \\
14 & Water $100 \%$ & E14 \\
\hline
\end{tabular}




\section{Determination of Antioxidant Activity}

Antioxidant activity was performed using the DPPH method previously described (Lee, Oh, Cho, \& Ma, 2015) with a slight modification. One hundred $\mu \mathrm{L}$ DPPH $125 \mu \mathrm{M}$ was added with $100 \mu \mathrm{L}$ S. polyanthum extract $(500 \mu \mathrm{g} / \mathrm{mL})$. The control sample was made by replacing DPPH $125 \mu \mathrm{M}$ with methanol. Similarly, as a blank, methanol was added instead of extracts. Each mixture was incubated for 30 minutes at room temperature and dark condition. The absorbance was measured using a microplate reader at $517 \mathrm{~nm}$, and the result expressed as \% antioxidant activity using the following formula:

\%Antioxidant activity $=[((\mathrm{B}-\mathrm{CB})-(\mathrm{S}-\mathrm{CS})) /(\mathrm{B}-\mathrm{CB})] \mathrm{x}$ $100 \%$

$B=$ Absorbance of blank; $C B=$ Absorbance of control blank; $S=$ Absorbance of sample, and $C S=$ Absorbance of control sample.

The $I C_{50}$ of active extracts was determined using linier regression by plotting the antioxidant activity (\%) ( $y$-axis) and the sample of extracts concentration ( $x$ axis). The series of concentrations of E1 and E3 were made between 250 to $3.91 \mu \mathrm{g} / \mathrm{mL}$, while E9 and E10 between 25 to $0.39 \mu \mathrm{g} / \mathrm{mL}$.

\section{UHPLC-HRMS analysis}

The extract with the higher antioxidant activity was chosen for UHPLC-HRMS analysis for bioactive compound characterization. The sample was dissolved in methanol, filtered with a $0.2 \mu \mathrm{M}$ membrane, and injected to the UHPLC system. The UHPLC-HRMS used in this study was Vanquish UHPLC system (Thermo Fisher Scientific, USA) using Electrospray ionization (ESI) with negative and positive modes and Q-Exactive plus Orbitrap-based mass spectrometers. The fragmentation was performed at collision energy 18, 35 and $53 \mathrm{Ev}$. The separation was done using accucore phenyl hexyl $(100 \times 2.1$ $\mathrm{mm}, 2.6 \mu \mathrm{m}$ ) (Thermo Fisher Scientific, USA). The detector used was diode array detector at wavelength $254 \mathrm{~nm}$ (Umar, Ratnadewi, Rafi, \& Sulistyaningsih, 2021). The sample was eluted at $0.4 \mathrm{~mL} / \mathrm{min}$ with mobile phase (A) acetonitrile and (B) $0.1 \%$ formic acid in water. The gradient profile of the mobile phase was: initialization $5 \% \mathrm{~A} ; 0-3.5 \mathrm{~min} 20 \% \mathrm{~A}$; 3.5 $5.0 \min 25 \% A_{;} ; 5.0-7.0 \min 25 \% A ; 7.0-8.5 \min 20 \%$ $A_{;}$8.5-9.5 min 30\% $A$; 9.5-12.5 min 30\% $A$; $12.5-$ $13.0 \mathrm{~min} 95 \% \mathrm{~A}_{;}$13.0-15.0 $\mathrm{min} 95 \% \mathrm{~A}_{;}$15.0-15.01 $\min 5 \% A$; and 15.01-16.0 min 5\% A. This mobile phase system was optimized following previous results (Har \& Ismail, 2012; Li et al., 2015) by using extract E9 as the most active extract. The system which gave the best separation and the highest peak number was chosen.

The MS spectra of the extracts were input into the Compound Discoverer 2.0 software (Thermo
Fisher Scientific, US) with the mode "untargeted metabolomics workflow". Several steps involved here was decribed as follow: retention time alignment, intensity normalization, unknown compound detection ( $\mathrm{mz}$ tolerance of $5 \mathrm{ppm}$ and minimum intensity 3000), unknown compound grouping, composition prediction, searching of mass list (linked with mzcloud database), fill in the gap, normalization of area and marking compound background. A database from $\mathrm{mzCloud}$ was used to identify the bioactive compound. The putative compounds were further analyzed using fragment ion search (FISh) mode in Compound Discoverer Software to identify the ion fragment.

\section{Statistical Analysis}

The quantitative data were analyzed using one-way analysis of variance (ANOVA) followed by Duncan's multiple range test. A $p$-value $<0.05$ indicates a significant difference in the measured response.

\section{RESULTS AND DISCUSSION \\ Antioxidant Activity}

Extraction and fractionation are essential stages in the bioactive compounds characterization, such as antioxidant, from a crude extract of natural resources. These steps aim to release the bioactive compound from the matrix sample and dissolved it in the extracting solvent. The bioactive compound can be present in a plant extract with a wide range of polarity, from the most non-polar to the most polar form. Extraction process with only using one type of solvent is not able to effectively release these diverse compounds from their matrix. Beside, identification of the target compound might be rather difficult as various different compounds are present in one extract. The targetted active compound which is a minor amount might be masked with non-active compound which present in larger concentration. Thus, extraction using solvent with various polarity would be more effective to release the compounds and to obtain extracts with semi-overlapping compounds in it. The last would make the active compound identification easier.

In this study, the extraction of S. polyanthum leaves was carried out using 3 solvents with different polarities and their combination: hexane (polarity index (PI) 0.1), acetone (PI 5.1), and water (PI 10.1) (Sadek, 2002). These solvents were eluted stepwise on $S$. polyanthum leaves which were placed in the stainless steel column to extract the compounds with the respective polarity. The antioxidant activity of $S$. polyanthum extract from this extraction was measured based on its ability to donate the electron to the 2,2-diphenyl-1-picrylhydrazyl (DPPH) radical. The alteration of the DPPH radical to non-radical was characterized by the transformation of the solution color from purple to yellow (Blois, 1958). 


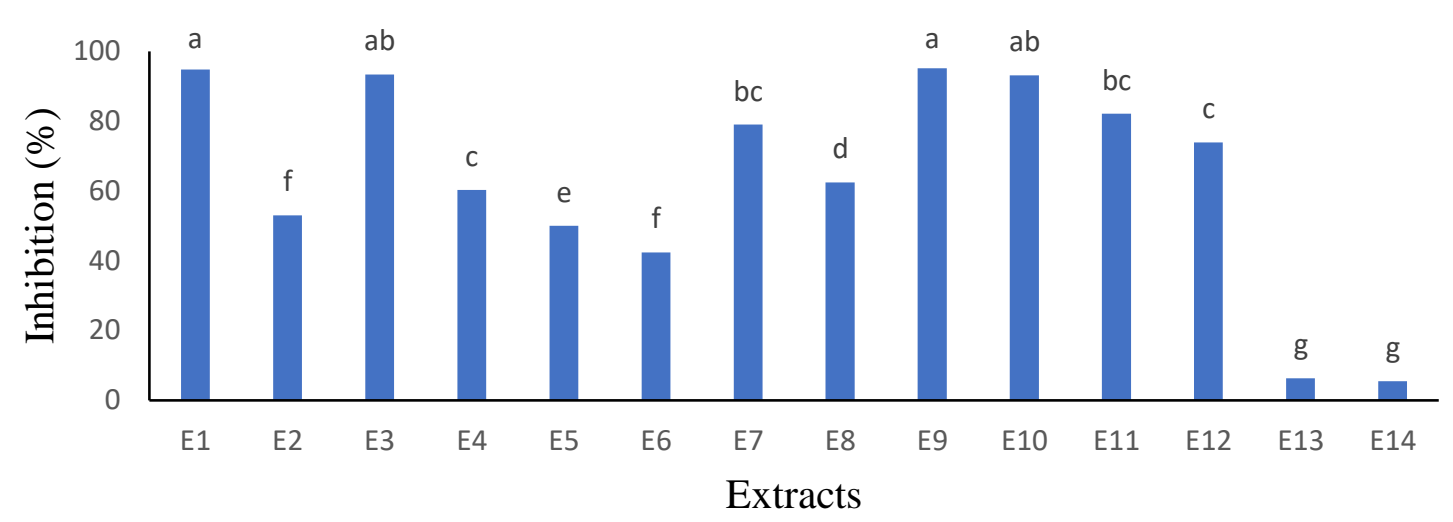

Figure 1. Antioxidant activity of $S$. polyanthum extracts at $500 \mu \mathrm{g} / \mathrm{mL}$. The list of abbreviation is provided in Table 1.

The results showed that E9 had the highest antioxidant activity at $500 \mu \mathrm{g} / \mathrm{mL}$ concentration, followed by E1, E3, and E10 with antioxidant activity value of $95.21,94.82,93.37$ and $93.19 \%$, respectively, while E13 and E14 had the lowest antioxidant activity (11.49 and $10.06 \%$, respectively) (Figure 1). The $\mathrm{IC}_{50}$ of these active extracts was then calculated and the results were as follow: 31.27 , 36.70, 3.01, and $8.5 \mu \mathrm{g} / \mathrm{mL}$, for E1, E3, E9, and E10, respectively. Interestingly, the $\mathrm{IC}_{50}$ of $\mathrm{E9}$ was not significantly different from ascorbic acid $\left(\mathrm{IC}_{50} 2.28\right.$ $\mu \mathrm{g} / \mathrm{mL})$. It indicated that E9 possessed similar radical scavenging activity power as ascorbic acid.

Based on antioxidant activity profile of $S$. polyanthum extracts presented in Figure 1, it can be seen that the antioxidant activity of relatively medium polar extracts (E9 and E10, obtained from the mixture of acetone and water extraction solvent) were higher than those of non-polar (hexane and hexane-acetone extracts) and polar extracts (water extracts). This is in agreement with previous studies which reported that $S$. polyanthum leaves extracted with semi-polar solvent (methanol) had higher antioxidant activity than other extract obtained from less polar solvent (petroleum ether and chloroform) and more polar solvent (water) (Widyawati et al., 2016). It was also found that $I_{50}$ of E9 obtained in this study $(3.01 \mu \mathrm{g} / \mathrm{mL})$, which was resulted from acetone-water (80:20) as a extraction solvent, was lower as compared to $I_{50}$ of $S$. polyanthum extracted using more semi-polar and nonpolar solvents such as ethyl acetate $\left(I_{50} 13.70\right.$ $\mu \mathrm{g} / \mathrm{mL})$, methanol $\left(\mathrm{IC}_{50} \quad 17.46 \mu \mathrm{g} / \mathrm{mL}\right)$, dichloromethane $\left(\mathrm{IC}_{50} 126.1 \mu \mathrm{g} / \mathrm{mL}\right)$, petroleum ether (23.08 $\mu \mathrm{g} / \mathrm{mL})$, chloroform (29.32 $\mu \mathrm{g} / \mathrm{mL})$ and hexane ( $\mathrm{IC}_{50} 136.7 \mu \mathrm{g} / \mathrm{mL}$ ) (Darusman et al., 2013; Hidayati et al., 2017; Widyawati et al., 2016). It might be denoted that acetone-water (80:20) was more efficient solvent to extract and to concentrate antioxidant compounds from S. Polyanthum leaves.

Despite a number of papers on S. polyanthum antioxidant activity were published, reports on the responsible active compounds are very rare. Only three common phenolic compounds were identified and their antioxidant activities were reported, i.e., gallic acid, vanillic acid, and syringic acid (Lelono \& Tachibana, 2013). Gallic acid and syringic acid exhibited higher inhibition of DPPH radical than vanillic acid $(95,89$, and $6 \%$, respectively).

\section{UHPLC-HRMS analysis}

The chemical profiles of 4 extracts with the highest antioxidant activity were characterized using UHPLCHRMS. The ionization process of the sample was performed using the electrospray ionization (ESI) technique in positive and negative modes. This technique was widely used to identify the bioactive compound from plant extract. It has several advantages such as good sensitivity, short sample preparation time, possible to easily identify the target metabolites by comparing their ion fragmentation pattern with the database (Ren, Zhang, Konga, \& Wang, 2018).

Chromatogram profiles of extracts with good activity (E1, E3, E9, and E10) showed that the appearing peaks quite varied. The appearing peaks in El had similar patterns to those of E3, which accumulated between retention time (RT) 14 to 15 minutes. The peaks at chromatogram of E9 were dominantly detected between RT 1 to 8 minutes, while the peaks in E10 were between 1 to 2 minutes. A peak with medium intensity at 13.9 was detected in both E9 and E10 (Figure 2).

The peaks appearing in the active extracts were then identified using the Compound Discoverer 2.0 software and $\mathrm{mzCloud}$ database. The identification of the compound was done by comparing the fragmented pattern of mass spectra of the sample with mzCloud database, while the unknown fragment was marked as unidentified. The putative structure was analyzed using FISh mode in Compound Discoverer software (Figure 3). To ensure the accuracy, the fragmentation patterns of mass spectra of the sample were further compared with the reported references or other online databases (METLIN, MoNA, and MassBank). 


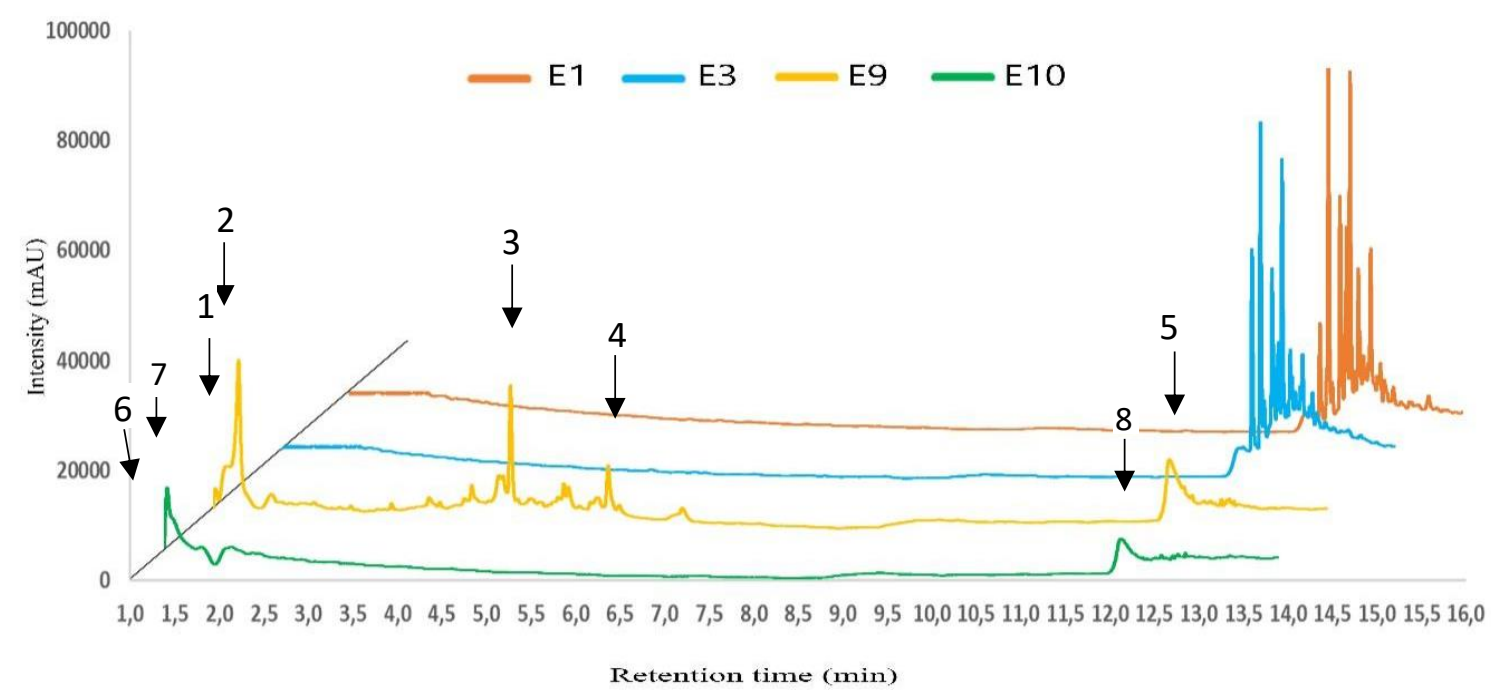

Figure 2. Overlays UHPLC-HRMS chromatograms of E1, E3, E9, and E10 at $254 \mathrm{~nm}$ (The peak intensity in each chromatogram was substracted with the peak intensity of the solvent). The list of abbreviation is provided in Table 1.
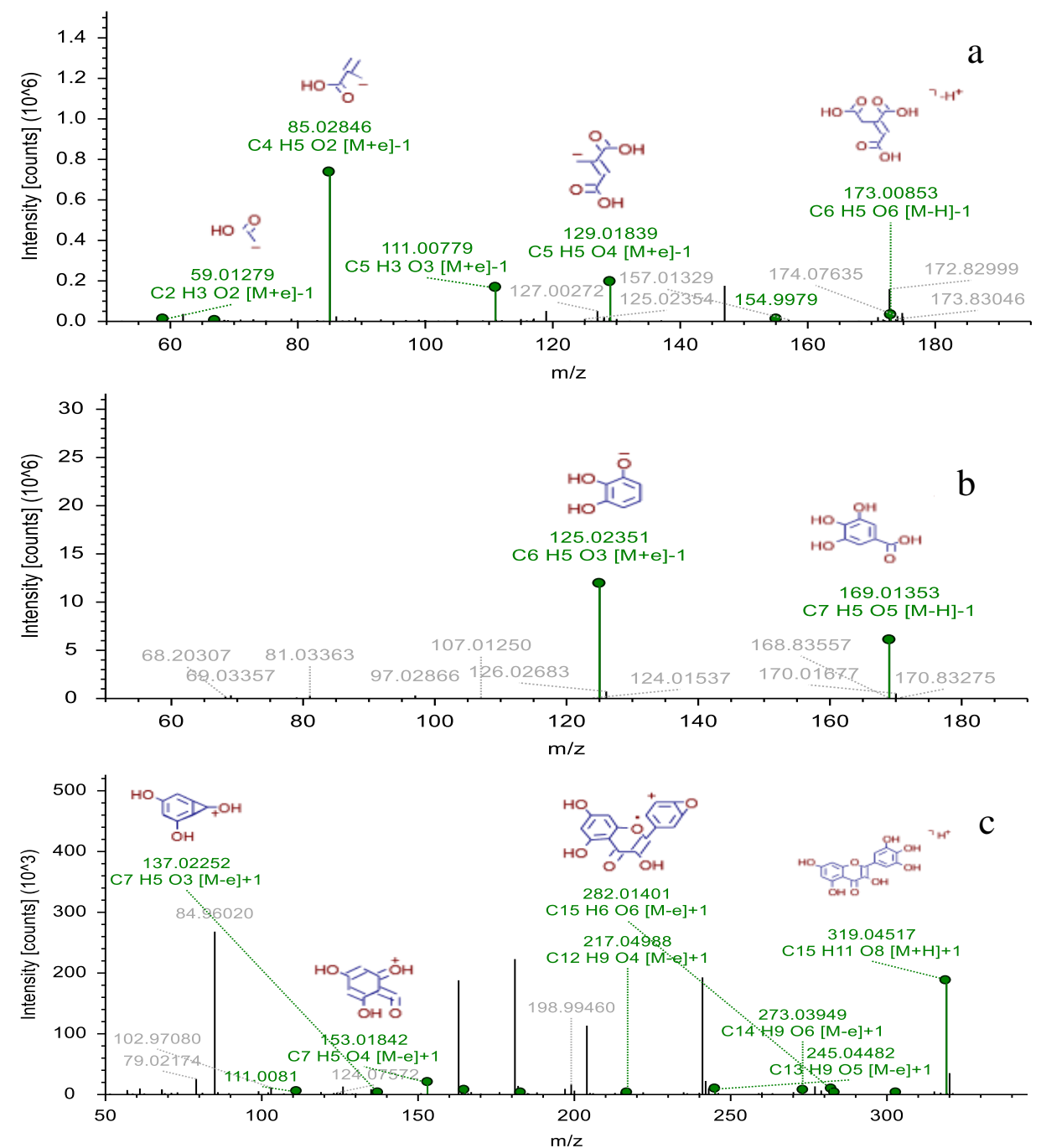

Figure 3. $M S^{2}$ spectra and the FISh fragment annotations of : a. trans-aconitic acid (peak number 1 at chromatogram of E9 and 6 at chromatogram of E10 in Figure 2); b. Gallic acid (peak number 2 at chromatogram of E9 and 7 at chromatogram of E10 in Figure 2); c. Myricetin (peak number 3 at chromatogram of E9 in Figure 2). 
E1 and E3 had several peaks appeared on the same RT, those are 14.07, 14.19, 14.34, 14.44, 14.48 , and $14.6 \mathrm{~min}$. Unfortunately, the fragmented pattern of mass spectra of all peaks was not detected by the database. Thus it was marked as unidentified (Figure 2). Due to the solvent used to obtain these extracts was non-polar (hexane 100\% for El and hexane: acetone $=80: 20$ for E3), further analysis using GC-MS might be necessary to characterize the compounds.

Chromatogram of Extract E9 contained several peaks as follow: $1.02 ; 1.35 ; 1.75 ; 3.88 ; 4.40 ; 5.01$; $5.65 ; 5.77 ; 6.30,7.32$ and 13.9 min (Figure 2). It can be seen that peaks at RT $1.02 ; 1.35 ; 5.01,6.30$, and 13.9 had a higher intensity than other peaks (black arrow number 1-5 in Figure 2). By using Compound Discoverer 2.0, the compounds at 1.02; 1.35 and 5.01 minutes were successfully identified as transaconitic acid, gallic acid and myricetin, respectively (Table 2). Unfortunately, the peak at RT 6.3 and 13.9 min remain unidentified.

Trans-aconitic acid was identified by ion precursor with $\mathrm{m} / \mathrm{z} 173.00853 \quad[\mathrm{M}-\mathrm{H}]^{-} \quad\left(\mathrm{C}_{6} \mathrm{H}_{6} \mathrm{O}_{6}\right)$. It was decarboxylated two times to form $\mathrm{C}_{5} \mathrm{H}_{5} \mathrm{O}_{4}(\mathrm{~m} / \mathrm{z}$ 129.01839) and $\mathrm{C}_{4} \mathrm{H}_{5} \mathrm{O}_{2}(\mathrm{~m} / \mathrm{z} 85.02846)$, respectively (Bylund, Norstrom, Essen, \& Lundstrom, 2007) (Figure 3a). Furthermore, gallic acid was identified with the presence of ion precursors $\mathrm{m} / \mathrm{z} 169.01 \mathrm{M}-\mathrm{H}]$ $\left(\mathrm{C}_{7} \mathrm{H}_{6} \mathrm{O}_{5}\right)$ (Figure $3 \mathrm{~b}$ ). This compound was fragmented by decarboxylated to form pyrogallol at $\mathrm{m} / \mathrm{z}$ 125.02, moreover another ion products formed with low intensity at m/z 97.03 and 69.03 (Basu, Patel, Janaa, \& Patela, 2013; Singh, Bajpaia, Kumara, Sharmac, \& Kumara, 2016). The compound identified at RT 5.01 was myricetin with ion precursor $\mathrm{m} / \mathrm{z} 319.04[\mathrm{M}-\mathrm{H}]^{+}$
$\left(\mathrm{C}_{15} \mathrm{H}_{11} \mathrm{O}_{8}\right)$ which then lost several hydroxy molecules especially at $B$ ring to form $\mathrm{C}_{15} \mathrm{H}_{6} \mathrm{O}_{6}(\mathrm{~m} / \mathrm{z} 282.01401)$ (Figure 3c). Other fragments of myricetin was found at $\mathrm{m} / \mathrm{z} 153.01842\left(\mathrm{C}_{7} \mathrm{H}_{5} \mathrm{O}_{4}\right)$ and $137.02252\left(\mathrm{C}_{7} \mathrm{H}_{5} \mathrm{O}_{3}\right)$.

The peaks on E10 chromatogram at RT 1.02, 1.32 and $13.9 \mathrm{~min}$ were analyzed using Compound Discoverer 2.0 and also compared to those of previous report. It was identified that the compounds at 1.02 and $1.35 \mathrm{~min}$ were similar with those of identified in E9, those are trans-aconitic acid and gallic acid, respectively. However, the area of these two compounds in E10 was lower than those of E9. Unfortunately, the compound at RT 13.9 min was not succesfully identified which then marked as an unknown compound.

Based on the area percentage (Table 2), gallic acid was supposed to have the major role in antioxidant activity both in E9 and E10. The presence of other compounds such as myricetin in E9 and trans-aconitic acid in E9 and E10 might strengthen the antioxidant activity of $S$. polyanthum. Previous study reported that gallic acid and myricetin had strong antioxidant activity with $\mathrm{IC}_{50}$ values of 11.4 and $10.7 \mu \mathrm{M}$, respectively (Li, Ouyang, Liang, \& Chen., 2019; Rafiee, Farhoosh, \& Sharif, 2018). Trans-aconitic acid was also reported elsewhere to have antioxidant activity with $\mathrm{IC}_{50} 70 \mu \mathrm{M}$ (Piang-Siong et al., 2016). There was other peaks which were thought as active compounds in E9 and E10. The peaks were found at RT $6.3 \mathrm{~min}$ (E9) and $13.9 \mathrm{~min}$ (E9 and E10). Unfortunately, because of the limited data base, the compound could not identified. Compounds in extract E1 and E3 are mostly unidentified, thus we excluded the profile from the Table 2.

Table 2. The identified peak and compound in extract E9*

\begin{tabular}{|c|c|c|c|c|c|c|c|c|}
\hline No & RT & Compound & $\begin{array}{l}\text { Area } \\
(\%)\end{array}$ & MW & Structure & $\begin{array}{l}\text { Precursor } \\
\text { ion }\end{array}$ & $\begin{array}{l}{[\mathrm{M}-\mathrm{H}]^{+/}} \\
\text {product ion } \\
(\mathrm{m} / \mathrm{z})\end{array}$ & $\begin{array}{l}\text { error } \\
\text { (ppm) }\end{array}$ \\
\hline 1 & 1.02 & $\begin{array}{l}\text { Trans-aconitic } \\
\text { acid }\end{array}$ & 7.69 & 174.01644 & $\mathrm{C}_{6} \mathrm{H}_{6} \mathrm{O}_{6}$ & 173.00853 & $\begin{array}{c}129.01839 ; \\
111.00779 ; \\
85.02846\end{array}$ & 0.234 \\
\hline 2 & 1.35 & Gallic acid & 45.82 & 170.02152 & $\mathrm{C}_{7} \mathrm{H}_{6} \mathrm{O}_{5}$ & 169.01344 & 125.02351 & 0.185 \\
\hline 3 & 5.01 & Myricetin & 20.40 & 318.03771 & $\mathrm{C}_{15} \mathrm{H}_{11} \mathrm{O}_{8}$ & 319.04498 & $\begin{array}{l}282.01401 ; \\
153.01842 ; \\
137.02252 .\end{array}$ & 0.005 \\
\hline 4 & 6.30 & Unknown & 6.4 & - & - & - & - & - \\
\hline 5 & 13.9 & Unknown & 13.09 & - & - & - & - & - \\
\hline \multicolumn{9}{|l|}{ E10 } \\
\hline 1 & 1.02 & $\begin{array}{l}\text { Trans-aconitic } \\
\text { acid }\end{array}$ & 8.07 & 174.01644 & $\mathrm{C}_{6} \mathrm{H}_{6} \mathrm{O}_{6}$ & 173.00853 & $\begin{array}{c}129.01839 ; \\
111.00779 ; \\
85.02846\end{array}$ & 0.234 \\
\hline 2 & 1.35 & Gallic acid & 65.32 & 170.02152 & $\mathrm{C}_{7} \mathrm{H}_{6} \mathrm{O}_{5}$ & 169.01344 & 125.02351 & 0.185 \\
\hline 3 & 13.9 & Unknown & 22.65 & - & - & - & - & - \\
\hline
\end{tabular}

${ }^{*}$ Compounds in extracts E1 and E3 were mosly unidentified, thus not presented in the Table 
The presence of gallic acid and myricetin in $S$. polyanthum leaves was reported by previous researchers (Har \& Ismail, 2012; Ismail, Ramli, Mohamed \& Ahmad, 2018; Lelono \& Tachibana, 2013; Syabana, Yuliana, Batubara \& Fardiaz, 2020). Trans-aconitic acid in $S$. polyanthum leaves was firstly reported in this study, nevertheless, the existence of this compound was reported in other Syzygium spp i.e Syzygium cumini (synonym Eugenia jambolana) (Sharmaa, Guptab, Bansald, \& Singha, 2015).

\section{CONCLUSIONS}

The dried leaves of $S$. polyanthum were extracted using solvents with different polarity in order to facilitate the active compounds characterization. Extracts of $S$. polyanthum which showed the highest DPPH antioxidant activity, those are E1, E3, E9, and E10, were successfully characterized using UHPLCHRMS. Trans-aconitic acid and gallic acid were identified in E9 and E10, while myricetin was identified in E9. All were previously reported to have radical scavenging activity. The existence of trans-aconitic acid in S. polyanthum was firstly reported. Extracts EI and E3 had almost similar activity and chromatogram profile. Unfortunately all peaks appeared in E1 and E3 remain unidentified. The uses of GC-MS might be usefull to characterize compounds in E1 and E3 because the extracts were obtained from non-polar solvents extraction.

\section{ACKNOWLEDGMENTS}

This work was supported by the Indonesia Endowment Fund for Education (LPDP), Ministry of Finance of Indonesia (Grant number PRJ6178/LPDP.3/2016).

\section{REFERENCES}

Basu, S., Patel, V. B., Janaa, S., \& Patela, H. (2013). Liquid chromatography tandem mass spectrometry method (LC-MS/MS) for simultaneous determination of piperine, cinnamic acid and gallic acid in rat plasma using a polarity switch technique. Analytical Methods Journal, 5(4), 967-976.

Blois, M. S. (1958). Antioxidant determinations by the use of a stable free radical. Nature, 181, 1199 1200.

Bylund, D., Norstrom, S. H., Essen, S. A., \& Lundstrom, U. S. (2007). Analysis of low molecular mass organic acids in natural waters by ion exclusion chromatography tandem mass spectrometry. Journal of Chromatography, 1176(1-2), 89-93.

Darusman, L. K., Wahyuni, W. T., \& Alwi, F. (2013). Acetylcholinesterase inhibition and antioxidant activity of Syzygium cumini, S. aromaticum and S. polyanthum from Indonesia. Journal of Biological Science, 13(5), 412-416.

Elya, B., Handayani, R., Sauriasari, R., Azizahwati, Hasyyati, U. S., Permana, I. T., \& Permatasari,
Y. I. (2015). Antidiabetic activity and phytochemical screening of extracts from Indonesian plants by inhibition of alpha amylase, alpha glucosidase and dipeptidyl peptidase IV. Pakistan Journal of Biological Sience, 18(6), 279-284.

Grosvenor, P. W., Gothard, P. K., McWilliam, N. C., Supriono, A., \& Gray, D. O. (1995). Medicinal plants from Riau province, Sumatra, Indonesia. Part 1: Uses. Journal of Ethnopharmacology, 45(2), 75-95.

Har, L. W., \& Ismail, I. S. (2012). Antioxidant activity, total phenolics and total flavonoids of Syzygium polyanthum (Wight) Walp leaves. International Journal of Medical and Aromatic Plants, 2(2), 219-228.

Hassan, L. E. A., Ahamed, M. B. K., Majid, A. S. A., Baharetha, H. M., Muslim, N. S., Nassar, Z. D., Majid, A. M. S. A. (2014). Correlation of antiangiogenic, antioxidant and cytotoxic activities of some Sudanese medicinal plants with phenolic and flavonoid contents. BMC Complementary and Alternative Medicine, 14, 406, 1-14.

Hidayati, M. D., Ersam, T., Shimizu, K., \& Fatmawati, S. (2017). Antioxidant activity of Syzygium polyanthum wight extracts. Indonesian Journal of Chemistry, 17(1), 49-53.

Islam, M. E., Islam, K. M. D., Billah, M. M., Biswas, R., Sohrab, M. H., \& Rahman, S. M. M. (2020). Antioxidant and anti-inflammatory activity of Heritiera fomes (Buch.-Ham), a mangrove plant of the Sundarbans. Advances in Traditional Medicine, 20,189-197.

Ismail, A., Ramli, N. S., Mohamed, M., \& Ahmad, W. A. N. W. (2018). Acute and sub-acute antihypertensive effects of Syzygium polyanthum leaf extracts with determination of gallic acid using HPLC analysis. Pharmacognosy Journal, 10(4), 663-671.

Ismail, A., \& Wan Ahmad, W. A. N. (2019). Syzygium polyanthum (Wight) Walp: A potential phytomedicine. Pharmacognosy Journal, 11 (2), 429-38.

Lee, K. J., Oh, Y. C., Cho, W. K., \& Ma, J. Y. (2015). Antioxidant and anti-inflammatory activity determination of one hundred kinds of pure chemical compounds using offline and online screening HPLC assay. Evidence Based Complementary Alternative Medicine, 165457, 1-13.

Lelono, R. A. A., \& Tachibana, S. (2013). Preliminary studies of Indonesian Eugenia polyantha leaf extracts as inhibitors of key enzyme for type 2 diabetes. Journal of Medical Sciences, 13(2), 103-110.

Li, B., Zhang, C., Peng, L., Liang, Z., Yan, X., Zhu, Y., \& Liv, Y. (2015). Comparison of essential oil composition and phenolic acid content of 
selected Salvia species measured by GC-MS and HPLC methods. Industrial Crops and Product, 69, 329-334.

Li, X., Ouyang, X., Liang, M., \& Chen, D. (2019). Comparative analysis of radical adduct formation (RAF) products and antioxidant pathways between myricetin-3-O-galactoside and myricetin aglycone. Molecules, 24(2769), $1-13$.

Loodu, S. S., \& Rupasinghe, H. P. V. (2019). Evaluation of antioxidant, antidiabetic and antiobesity potential of selected traditional medicinal plants. Frontiers in Nutrition, 6(53), $1-11$.

Muthia, R., Suganda, A., \& Sukandar, E. (2017). Angiotensin-1 converting enzyme (ACE) inhibitory activity of several Indonesian medicinal plants. Research Journal of Pharmaceutical Biological and Chemical Sciences, 8(Suppl. 1), 192-199.

Perumal, S., Mahmud, R., Piaru, S. P., Chai, L. W., \& Ramanathan, S. (2012). Potential antiradical activity and cytotoxicity assessment of Ziziphus mauritiana and Syzygium polyanthum. International Journal of Pharmacology, 8(6), 535-541.

Phongpaichit, S., Nikom, J., Rungjindamai, N., Sakayaroi, J., Hutadilok-Towatana, N., Rukachaisirikul, V., \& Kirtikara, K. (2007). Biological activities of extracts from endophytic fungi isolated from Garcinia plants. FEMS Immunology and Medical Microbiology, $57(3)$, 517-525.

Piang-Siong, W., Caro, P. D., Marvilliers, A., Chasseray, X., Payet, B., Singh, A. S. C., \& Illien, B. (2016). Contribution of trans-aconitic acid to $\mathrm{DPPH} \bullet$ scavenging ability in different media. Food Chemistry, 1(214), 447-452.

Rafiee, S. A., Farhoosh, R., \& Sharif, A. (2018). Antioxidant activity of gallic acid as affected by an extra carboxyl group than pyrogallol in various oxidative environments. European Journal of Lipid Sciences and Technology, 120(11), 1-8.

Rahim, E. N., Ismail, A., Omar, M. N., Rahmat, U. N. \& Ahmad, W. A. (2018). GC-MS analysis of phytochemical compounds in Syzygium polyanthum leaves extracted using ultrasoundassisted method. Pharmacognosy Journal, 10(1), 110-119.

Ren J. L., Zhang, A. H., Konga, L., \& Wang, X. J. (2018). Advances in mass spectrometry-based metabolomics for investigation of metabolites. Royal Society of Chemistry Advances, 8(40), 22335-22350.
Sadek P.C. 2002. The HPLC Solvent Guide. 2nd ed. New York, NY: John Wiley \& Sons.

Sharmaa, R. J., Guptab, R. C., Bansald, A. K., \& Singha, I. P. (2015). Metabolite fingerprinting of Eugenia jambolana fruit pulp extracts using NMR, HPLC-PDA-MS, GC-MS, MALDI-TOF-MS and ESI-MS/MS Spectrometry. Natural Product Communications, 10(6), 969-976.

Singh, A., Bajpaia, V., Kumara, S., Sharmac, K. R., \& Kumara, B. (2016). Profiling of gallic and ellagic acid derivatives in different plant parts of Terminalia ariuna by HPLC-ESI-QTOF-MS/MS. Natural Product Communications, 11 (2), 239244.

Sulistiyani, Falah, S., Wahyuni, W. T., Sugahara, T., Tachibana, S., \& Syaefudin. (2014). Cellular mechanism of the cytotoxic effect of extracts from Syzygium polyanthum leaves. American Journal of Drug Discovery and Development, $4(2), 90-101$.

Syabana, M. A., Yuliana, N. D., Batubara, I., \& Fardiaz, D. (2020). Antidiabetic activity screening and $\mathrm{nmr}$ profile of vegetable and spices commonly consumed in Indonesia. Food Science and Technology (Campinas), in press, doi: $10.1590 /$ fst. 14120.

Umar, A. H., Ratnadewi, D., Rafi, M., Sulistyaningsih, Y. C. (2021). Untargeted metabolomics analysis using FTIR and UHPLC-Q-Orbitrap HRMS of two Curculigo species and evaluation of their antioxidant and $\alpha$-glucosidase inhibitory activities. Metabolites, $11(1), 42-58$.

Widyawati, T., Roslan, N. A. B., Yusoff, N. A., Asmawi, M. Z., \& Ahmad, M. (2016). The evaluation of antioxidant and free radical scavenging activities of Eugenia polyantha leaves extracts. International Journal of Chemtech Research, 9(9), 465-471.

Widyawati, T., Yusoff, N. A., Asmawi, M. Z., \& Ahmad, M. (2015). Antihyperglycemic effect of methanol extract of Syzygium polyanthum (Wight.) leaf in streptozotocininduced diabetic rats. Nutrients, 7(9), 77647780.

Yadav, S. (2018). Correlation analysis in biological studies. Journal of the Practice of Cardiovascular Sciences, 4(2), 116-121.

Yuliana, N. D., Khatib, A., Verpoorte, R., \& Choi, Y. H. (2011). Comprehensive extraction method integrated with NMR metabolomics: a new bioactivity screening method for plants, A1 receptor binding compounds in Orthosiphon stamineus Benth. Analytical Chemistry, 83(17), 6902-6909. 